\title{
Determination and evaluation of the parameters influencing the virtual educational costs
}

\author{
Parisa Mokhtar Makeli ${ }^{a^{*}}$, Masoud Babakhani ${ }^{\mathrm{b}}$ and Masoumeh Bodaghic
}

${ }^{a}$ Department of Industrial Engineering, Virtual Unit, Iran University of Science \& Technology, Tehran, Iran

${ }^{b}$ Department of Industrial Engineering, Islamic Azad University, Karaj Branch, Karaj, Iran

${ }^{c}$ Department of Industrial Engineering, Amirkabir University of Technology, Tehran, Iran

\begin{tabular}{|c|c|}
\hline A R T I C L E I N F O & A B S T RACT \\
\hline $\begin{array}{l}\text { Article history: } \\
\text { Received July } 30,2011 \\
\text { Received in Revised form } \\
\text { September, 15, 2011 } \\
\text { Accepted 17 September } 2011 \\
\text { Available online } \\
18 \text { September } 2011 \\
\text { Keywords: } \\
\text { Activity based cost } \\
\text { E-learning } \\
\text { Distance learning } \\
\text { Regression analysis }\end{array}$ & $\begin{array}{l}\text { E-learning has recently attracted many people specially those who cannot attend traditional } \\
\text { educational programs for different reasons such as busy schedule, long distance, etc. There is } \\
\text { also a growing interest among many public universities to develop such programs in addition to } \\
\text { their regular business activities. The primary question is to know how much a program cost and } \\
\text { what is the most important factors affecting the cost of e-learning. In this paper, we present an } \\
\text { empirical study the measure the effects of different items on the cost of e-learning programs. } \\
\text { The proposed study of this paper gathers the necessary cost components of three governmental } \\
\text { universities located in city of Tehran/Iran. We choose ten different cost items for our analysis } \\
\text { and using some statistical test determine the most important ones. The preliminary study of this } \\
\text { paper indicates that seven cost items play essential role on determining the cost of e-learning, } \\
\text { which includes utilities, internet connection and network, employee payment, software \& } \\
\text { licensing, payments of instructors and their assistants, hardware equipments and other overhead } \\
\text { expenditures. This could help us determine the precise cost of e-learning using activity cost } \\
\text { method. }\end{array}$ \\
\hline
\end{tabular}

\section{Introduction}

During the past two decades, there have been tremendous efforts on developing educational studies through internet and its applications. Distance learning has many advantages such as removing unnecessary transportation costs (Pohlen \& La Londe, 1994), saving time, creating opportunities for many people who cannot attend regular educational studies, etc. The idea of e-learning is not new and it was originally started in 19th century, where some distance learning schools were established in North American and European countries using post office services. First collegiate distance learning based post office was established in 1892. In the mid-twentieth century, there was also a variety of educational programs, which was presented to different audiences. Since then, e-learning has changed significantly since many people from different countries could participate in such courses from various countries. They could share their opinions and learn from their experiences especially in

\footnotetext{
* Corresponding author. Tel: +0982144907194

E-mail addresses: pamomaleki@yahoo.com (P. Maleki) 
management level skills. Physicians could exchange their experience using internet facilities and prescribe suitable medications for the patients who cannot travel.

One obvious advantage of learning over internet facilities is to reduce the cost of learning as much as possible. Learning through internet reduces many physical infrastructures and replaces them with computers and technology. Many human resources such as university professors across the world could participate in these universities and contribute with no need to travel, physically. Present age of exact global competition and quickly improving technologies and improving information systems has forced companies to use new business management techniques (Baykasoglu \& Kaplanoglu, 2008). Many of courses are normally prepared in different forms of sharable content object (SCO) and they can be shared among many students over a reasonable number of educational terms depending on the nature of course.

For instance, we can produce a comprehensive SCO for a course named fundamentals of physics and use it virtually for years since the content of this course does not change, significantly. In such a case, the cost of teaching a course will be reduced, remarkably. One primary question is on how to calculate the cost of an educational program when it is offered over the internet. Traditional method for measuring the cost of educational program does not provide reliable figures since various courses have virtually different dynamic contents. There are other issues affecting the cost of educational learning such as the amount of time needed for live attendance of instructors, the need for special labs, etc. Therefore, we understand that the cost of producing a course needs a more precise method such as activity based cost (ABC) method. In ABC method, we need for an instrument to create a link between logistical process information and financial information (Van Damme \& Van Der Zon, 1999).

There is no doubt that a detailed analysis on the cost of production could help e-learning organizations select suitable programs and $\mathrm{ABC}$ method could contribute for making better managerial decisions. These days, there is a growing competition among universities offering elearning opportunities. Obviously, there are many market structures like business competition enforced companies to manage their costs. Under strong competition with ever-increasing efficiency and effectiveness, they need to become leaner, responsive and agile (Agrawal \& Mehra, 1998). Then high-quality services/ products in a short time with lowest possible cost is one of the best advantage that a company should be able to provide. In order to provide lower costs, exact cost information is critical for every aspect of business, and it affects the pricing policies and performance reviews (Gupta \& Galloway, 2003). According to Nachtmann and Al-Rifai (2004), ABC helps many service organizations to make better decisions based on an improved understanding of their product cost by enabling services.

There are many applications of $\mathrm{ABC}$ in manufacturing organizations and about their decision processes (Zhuang \& Burns, 1992; Dhavale, 1993; Koltai et al., 2000; O“ zbayrak et al., 2004; Kirche et al., 2005; Satoglu et al., 2006). ABC was introduced in late 1980s' with the studies of Cooper (1988a, b), Cooper and Kaplan (1988) and Johnson and Kaplan (1987). Direct costs and indirect costs are based on cost calculation of the products and/or services in traditional costing to find the individual cost of each element. Conventional cost accounting involves collecting indirect costs from departments and then allocates them to products or services (Tsai \& Kuo, 2004). ABC method is used when the overhead cost is a significant portion of the product.

In such a case, using single-volume cost motivation to allocate indirect costs to the cost object might not be enough method for a detailed cost analysis in many conditions. Raw material usages are frequently considered as a cost motivation in traditional costing and a single cost driver is generally used for the distribution of overheads. In addition to this, product costs are fairly high when the accounting is performed with traditional cost accounting especially for the organizations where the proportion of overheads to total costs (Tsai \& Kuo,2004; Gunasekaranand \& Sarhadi, 1998). On the 
other hand, the main premise behind $\mathrm{ABC}$ is to classify overheads or indirect costs and to allocate them to products or services based on the required activities to produce these products (Raz \& Elnathan, 1999).

Presently, there are many universities in Iran offering e-learning courses including Shiraz University and Science and Technology, Khajenasir University, Amir Kabir University and Iran University of Science and Technology. In this paper, we present an empirical study to measure the relative cost of e-learning components based on ABC and traditional methods. The proposed study of this paper is implemented for a real-world case study of some governmental universities located in Tehran/Iran. This paper is organized as follows. We first present details of our implementation in section 2 and the results of the survey is included in section 3. Concluding remarks are given in the last to summarize the contribution of the paper.

\section{The proposed model}

$\mathrm{ABC}$ assumes that cost objects including products, product lines, processes, customers, channels, markets and so on are costs to product and/or services differ from the traditional cost accounting (TCA) (Tsai \& Kuo, 2004).

The accuracy of $A B C$ can vary according to its focus. The focus might be on the product, customer or a combination of both. Resources include indirect costs of the organizations and they are allocated to the activity centers (Fig. 1). Resource drivers are used during allocation of the resources to the activity centers (Baykasoglu \& Kaplanoglu, 2008).

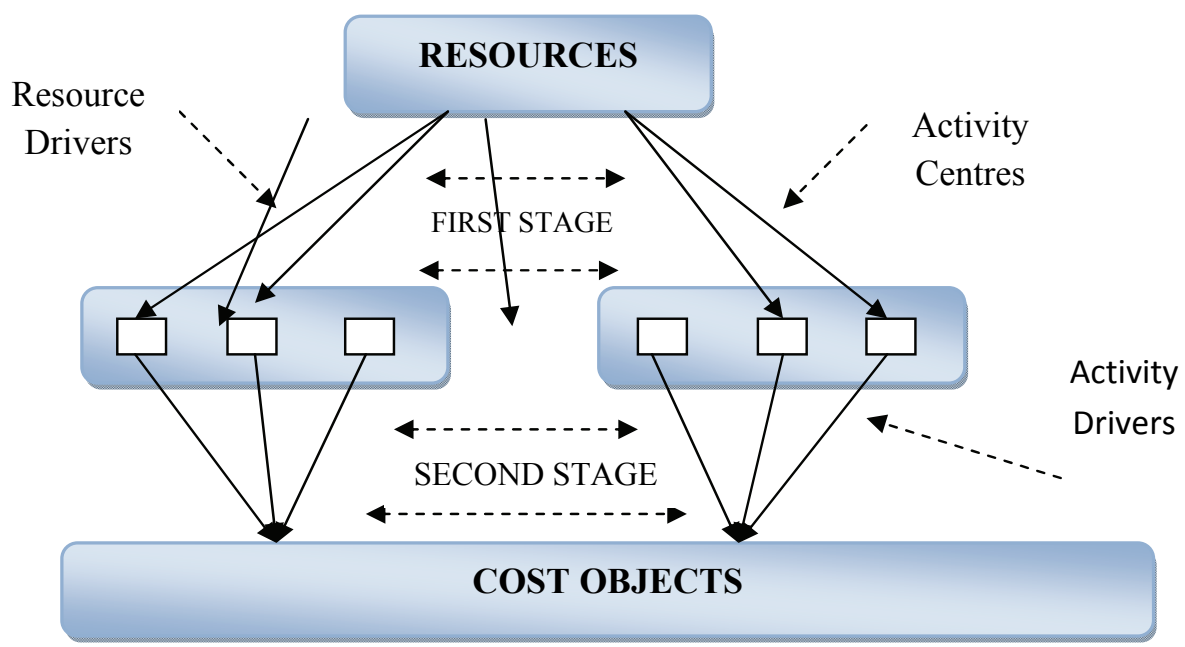

Fig. 1. Cost assignment procedure in ABC (Tsai \& Kuo, 2004)

The implementation of $\mathrm{ABC}$ method for service organizations is very difficult because in service organizations, identifying cost of driving and its effectiveness for each activity is not easily measured. We need to first identify cost drivers and then allocate the costs based on an appropriate method. For identifying the driving cost the method of interview with experts and managers have been used. Therefore, using the organizational chart of the universities and studying administrative structure of universities, all parts that serve to the electronic students directly or indirectly are identified. In this paper, we use experts' opinions (DMs) to find the best candidates for cost drivers. There are some challenges for our implementation since most e-learning units in Iran operates as a subsidiary of bigger universities and some of the cost components are common between the e-learning unit and other university units such as security, utility, administration, etc. 
In such cases, we could rely on what DM thinks on how to allocate the cost. We have gathered the necessary data from three universities of Amirkabir University, Science and Technology University and University of Shahid Beheshti. There are some common features among these universities. First, all three universities accept students in the technical-engineering fields and most of them accept students in the field of master of business administration. Second, they are all public universities with similar structure. Third, all universities have at least two years of experiencing of this kind of students.

There are different methods of accepting students at the universities such provisionary or regular. Note that students normally enter public universities by participating in national exams and students who enter through regular policy are called regular students. There was another method of accepting students, where the universities separately made an announcement and chose students based on some interview. The students who entered the university must take some additional courses and they become regular student when they pass their first term courses, successfully. During the first term, these students are called provisionary until they reach the minimum requirements. Therefore, it is clear that the cost of education for these students could be different from the other students.

The implementation of $\mathrm{ABC}$ analysis normally requires three cost components of direct payment, direct materials and overhead costs.

\subsection{Direct materials}

One of the most important components of direct materials is associated with preparation of SCOs. These SCOs are necessary since the whole e-learning program depends on these SCOs. There are different standards for preparing a SCO and the payment depends on the quality of the final product but we can calculate the average cost of SCOs, statistically.

\subsection{Direct payment}

Most instructors are required to attend in electronic classes through internet facilities and the payments are made based on the amount of time they spend on their classes. On the other hand, the payment per hour is different from one instructor to another since the pay is a function of instructors' academic evaluation. Nevertheless, we may calculate the hourly payment based on gathering the data and the average number of hours can also be measured statistically.

\subsection{Overhead cost}

The overhead is indeed the most important part of the cost components of e-learning courses. It includes various items including maintenance cost, software licensing, advertisement, utility, internet connection, employee salary, depreciation, training, etc.

Next section, we explain details of our computations for each part of the cost of e-learning.

\section{The results}

The proposed model of this paper gathered the necessary data from three e-learning units located in Tehran/Iran. The study chose engineering programs with various cost items to analyze the cost of elearning program using $\mathrm{ABC}$ technique. The primary question of this survey is to determine the most influencing cost items affecting the cost of e-learning programs. We have discussed all the necessary issues and determined the fee paid to instructors and employees as the direct payment. The band wide can be considered as the first important direct material. The other indirect costs considered in our survey include depreciation of hardware facilities, servers, software packages, buildings and SCOs. 
The cost of the necessary equipments, hardware equipments and other overhead costs are also considered in our survey. We have collected the information of ten semesters from 2005 to 2010. In order to determine the most influencing factors on the cost of e-learning program, we have implemented an analysis on time series data using panel data gathered from three universities. Table 1 introduces the names of all ten variables in our analysis.

Table 1

The names of ten variables

\begin{tabular}{|c|c|c|c|}
\hline Variable & Description & Variable & Description \\
\hline$x_{1}$ & Utilities & $x_{6}$ & The payment for teachers and their assistants \\
\hline$x_{2}$ & Online equipments & $x_{7}$ & Hardware equipments \\
\hline$x_{3}$ & $\begin{array}{l}\text { Internet connection and } \\
\text { network }\end{array}$ & $x_{8}$ & Depreciation \\
\hline$x_{4}$ & Employee payment & $x_{9}$ & Server equipments \\
\hline$x_{5}$ & Software \& Licensing & $x_{10}$ & Other overhead costs \\
\hline
\end{tabular}

We have performed statistical test using panel data with Eviews 7 statistical software package and Table 2 summarizes the results of our analysis.

Table 2

The results of our analysis

\begin{tabular}{cllll}
\hline Variable & Coefficient & Std. Error & t-student & Prob. \\
\hline $\mathrm{C}$ & 499464.6 & 68022.95 & 7.342590 & 0.0001 \\
$x_{1}$ & 7.810480 & 1.917454 & 4.073359 & 0.0036 \\
$x_{3}$ & 1.249200 & 0.133427 & 9.362452 & 0.0000 \\
$x_{4}$ & 1.148947 & 0.045336 & 25.34306 & 0.0000 \\
$x_{5}$ & 2.492611 & 0.416409 & 5.985968 & 0.0003 \\
$x_{6}$ & 0.728769 & 0.089546 & 8.138509 & 0.0000 \\
$x_{7}$ & 1.106801 & 0.439935 & 2.515832 & 0.0360 \\
$x_{10}$ & 1.959311 & 0.307909 & 6.363285 & 0.0002 \\
\hline
\end{tabular}

As we can observe from the results of our regression analysis, the effects of seven variables are considered statistically meaningful when the level of significance is less than 0.01 . In other word, the cost of e-learning is a function of utilities, internet connection and network, employee payment, software \& licensing, payments of instructors and their assistants, hardware equipments and other overhead expenditures. Therefore, we can conclude that $\mathrm{ABC}$ cost analysis must be performed in details for these seven variables.

\section{Conclusions}

In this paper, we have presented an empirical study to measure the effects of different items on the cost of e-learning programs. The proposed study of this paper has gathered the necessary cost components of three governmental universities located in city of Tehran/Iran. We have chosen ten different cost items for our analysis and using some statistical tests, we found that seven cost items play essential role on determining the cost of e-learning including utilities, internet connection and network, employee payment, software \& licensing, payments of instructors and their assistants, hardware equipments and other overhead expenditures. This could help us determine the precise cost of e-learning using activity cost method. 


\section{References}

Agrawal, S.P., \& Mehra, S. (1998). Cost management system: an operational overview. Managerial Finance, 24 (1), 60-78.

Baykasoglu, A., \& Kaplanoglu, V. (2008). Application of activity-based costing to a land transportation company: A case study. Production Economics, 116, 304-324.

Cooper, R. (1988). The rise of activity based costing-Part One: What is an activity based cost system? .Journal of Cost Management, 2(2), 45-54.

Cooper, R., \& Kaplan, R.S. (1988). How cost accounting distorts product costs. Management Accounting, 69 (10), 20-27.

Dargay, J. (2007). The effect of prices and income on car travel in the US. Transportation Research Part A, 41 (2007), 949-960.

Gunasekaran, A., \& Sarhadi, M. (1998). Implementation of activity-based costing in manufacturing. International Journal of Production Economics, 56-57, 231-242.

Gupta, M., \& Galloway, K. (2003). Activity-based costing/management and its implications for operations management. Technovation, 23, 131-138.

Johnson, H.T., \& Kaplan, R.S. (1987). Relevance Lost: The Rise and Fall of Management Accounting. Harvard Business School Press. Boston

Nachtmann, H., \& Al-Rifai, M.H. (2004). An application of activity based costing in the air conditioner manufacturing industry. The Engineering Economist, 49, 221-236.

Pohlen, T.L., \& La Londe, B.J. (1994). Implementing activity-based costing (ABC) in logistics. Journal of Business Logistics, 15 (2), 1-23.

Raz, T., \& Elnathan, D. (1999). Activity-based costing for projects. International Journal of Project Management, 17 (1), 61-67.

Tsai, W.H., \& Kuo, L. (2004). Operating costs and capacity in the airline industry. Journal of Air Transport Management, 10 (4), 269-275

Zhuang, L., \& Burns, G. (1992). Activity-based costing in non-standard route manufacturing. International Journal of Operations and Production Management, 12 (3), 38-60.

Van Damme, D.A., \& Van Der Zon, F.L.A. (1999). Activity based costing and decision support. International Journal of Logistics Management, 10 (1), 71-82.

Woldeamanuel, M.G., Cyganski, R., Schulz, A., \& Justen, A. (2009). Variation of households' car ownership across time: application of a panel data model. Transportation, 36, 371-387. 